\title{
The 's' in Unesco seeks out a new role
}

[PARIS] The United Nations Educational, Scientific and Cultural Organization (Unesco) has set up a 50-strong International Scientific Advisory Board to give working scientists a greater say in a planned reform of the way the agency supports science.

The board, which met in Paris for the first time this week, is made up of eminent scientists from industrialized and developing countries. They include Nobel laureates Carlo Rubbia, Ilya Prigogine, Jean Dausset, Georges Charpak, Paul Berg and Werner Arber, who chairs the board and who is also president of the International Council of Scientific Unions (ICSU).

According to Federico Mayor, Unesco's director general, the board's main role will be to advise on reform of the agency's scientific activities, and also to help prepare the agenda for a UN world science summit which Unesco plans to hold in 1999 in collaboration with ICSU.

Mayor says that the beginning of the new millennium is an appropriate time to put the ' $\mathrm{s}$ ' back in Unesco, alluding to the fact that science was not included in the original title. Although 'Uneco' was eventually changed to 'Unesco' - after the British scientists Joseph Needham and Julian Huxley had argued that science was part of culture - many argue that science has since become the weakest area of the agency's activities.

“To see Unesco's role in science you have to go back in history," says David Ottoson, secretary general of the International Brain Research Organization, and a member of the new advisory board, alluding to Unesco's heyday in the early post-war years, when it was instrumental in creating CERN, the European Laboratory for Particle Physics.

\section{Useful but less visible work}

Since then Unesco's science programme has been "very weak", says Ottoson. But he says it has nevertheless done much useful, though less visible, work through its support for ICSU. He points out that science has been a poor relation to education within the agency, and argues the need to alter this situation.

Others say that Unesco's impact on science is doomed to remain small, given its administrative structure and relatively low funding compared to national research budgets. Unesco's budget for 1996 and 1997 is $\$ 518.4$ million - of which $\$ 84$.1 million is dedicated to support for science - plus $\$ 290$ million from other UN agencies and member states.

This is about equal to the budget of a large university, and a drop in the ocean compared with the needs of developing countries alone. The budget is much less than is needed to implement comprehensive science programmes in Unesco's 185 member states.

The funding problem is compounded by the continued absence from membership of Unesco of both the United States and the United Kingdom.

The agency seems to have woken up to its limitations. In Unesco, the Will to Reform, a strategy document published last year, it pointed out that since 1988 it had trimmed its number of programmes from 392 to 139. The aim was to meet the demand of member states that it "avoid channelling money into a variety of projects having little or no impact, and concentrate its activities on fewer but better conceived programmes".

The agency also intends to stop directly supporting research projects apart from small amounts given to projects in poor countries, which often demand a juste retour on their Unesco subscription, according to

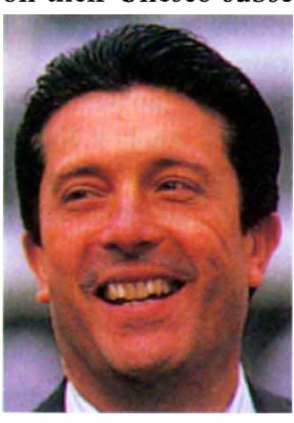

Mayor: values Unesco's role on ethical issues.

qualifying projects with a Unesco 'label' that will help to attract other funding.

This 'hands-off' approach also reflects the fact that staff cuts at Unesco have curbed a tendency to create new bureaucratic structures to manage new projects. Staff numbers have fallen from more than 3,000 in 1987 to around 2,200 today, while the science division has just 270.

Getting outside scientists involved in setting strategy through the new advisory board is one way to compensate for Unesco's lack of staff and professional expertise. Panels of outside scientists have proved their usefulness in Unesco's well respected intergovernmental commissions, such as those that coordinate international research on oceanography, hydrology and geology.

Staff cuts have taken their toll on morale. One observer claims that many of the best people have now gone, and that the cuts have undermined the agency's intellectual capacity. "It's a desert here," claims one official at Unesco's Paris headquarters. "At six o'clock, everyone has gone home except the cleaners."

Besides adjusting Unesco's administration to financial realities, the main challenge still facing Mayor is to adapt the organization's goals to the contemporary world. Mayor refers to the need "to get back to our constitution, which says we must build peace through transfer of knowledge". But as Julian Huxley, Unesco's first director general, once remarked, the constitution amounts to "a starry-eyed hope rather than a practical guide to action".

Critics argue that top-down organizations such as Unesco are increasingly irrelevant in a post-Cold-War world marked by decentralization - exemplified by the Internet - and a shift in research goals from strategic and ideological ends to innovation and economic competitiveness. One critic points out that the emerging economies of Asia developed their technological economies independently of Unesco.

Similarly, many large research organizations see no need to go through Unesco. Patricia Psuchitani, from the Africa Division of the US National Science Foundation, says that it has no contact with the agency, preferring to establish cooperative research programmes through bilateral and multilateral agreements.

\section{A potentially unique role}

But some hardened critics of Unesco nonetheless agree that in principle it remains uniquely placed as the only international intergovernmental agency with an explicit remit to promote fundamental science. They say it has a vital philosophical role in the "battle of ideas" to persuade developing countries of the need to invest in a science base if they are to profit from aid programmes and technological progress. "It would be a great pity" if Unesco were to be dissolved, says one critic.

Mayor sees Unesco's philosophical role as an international forum for debate on the ethical issues surrounding scientific progress as a major plank in the agency's future. Indeed, its International Bioethics Commission, with 50 members from developing and industrialized countries (onethird of whom are scientists), has been widely acknowledged as a success.

The commission has prepared a draft of a "universal declaration on the human genome and human rights" which will be submitted for approval to the Unesco General Assembly later this year. Mayor would like to extend this approach to other areas, by creating similar forums of scientists, lawyers, intellectuals and other representatives of society to discuss at a world level the social aspects of issues such as energy, information technology and biotechnology.

"Science is a political issue and part of the decision-making process, and we need to take into account the social dimension," says Mayor. "This is the main contribution Unesco can make."

DeclanButler 